\title{
Nonintubated uniportal thoracoscopic segmentectomy for lung cancer
}

\author{
Ming-Hui Hung, MD, MS, ${ }^{\text {a,b }}$ Ya-Jung Cheng, MD, PhD, ${ }^{\mathrm{a}}$ Hsao-Hsun Hsu, MD, $\mathrm{PhD},{ }^{\mathrm{c}}$ and \\ Jin-Shing Chen, MD, PhD, ${ }^{\mathrm{c}, \mathrm{d}}$ Taipei, Taiwan
}

Uniportal video-assisted thoracoscopic surgery (VATS) and nonintubated anesthesia are new frontiers in minimally invasive thoracic surgery. ${ }^{1-5}$ In light of our previous experience with nonintubated conventional 3-port VATS segmentectomy, ${ }^{3,4}$ we further explored the feasibility of nonintubated uniportal VATS segmentectomy.

\section{CLINICAL SUMMARY}

A 41-year-old nonsmoking woman was transferred to our hospital for an indeterminate pulmonary nodule. She had an unremarkable medical history but a family history of lung cancer. Thoracic computed tomography (CT) and positron emission tomography both showed a $7-\mathrm{mm}$ ground-glass opacity in the right upper lobe, consistent with stage IA lung cancer (Figure 1, A). The preoperative forced expiratory volume in 1 second was $81 \%$. After discussion with our surgical team, the patient opted for nonintubated anesthesia with uniportal VATS.

Before surgery, the location of the lesion was determined with CT-guided dye marking with $0.2 \mathrm{~mL}$ of patent blue V (Guerbet, Aulnay-sous-Bois, France) at the surface of the right upper lobe. Our nonintubated anesthesia included standard monitoring: electrocardiography, arterial blood pressure, pulse oximetry, capnography, and bispectral index monitoring. ${ }^{4}$ An intravenous injection of $50 \mu \mathrm{g}$ fentanyl and a target-controlled infusion of propofol were administered to achieve a bispectral index between 40 and $60 .{ }^{4}$ During the procedure, the patient breathed oxygen spontaneously through a ventilation mask. ${ }^{4}$

Subsequently, the patient was placed in the left lateral decubitus position. A single 3 -cm incision was made in

\footnotetext{
From the Department of Anesthesiology, ${ }^{\mathrm{a}}$ National Taiwan University Hospital and National Taiwan University College of Medicine, Taipei, Taiwan; the Graduate Institute of Clinical Medicine, ${ }^{\mathrm{b}}$ National Taiwan University College of Medicine, Taipei, Taiwan; the Division of Thoracic Surgery, ${ }^{c}$ Department of Surgery, National Taiwan University Hospital and National Taiwan University College of Medicine, Taipei, Taiwan; and the Department of Traumatology, ${ }^{\mathrm{d}}$ National Taiwan University Hospital and National Taiwan University College of Medicine, Taipei, Taiwan.

Disclosures: Authors have nothing to disclose with regard to commercial support.

Received for publication May 6, 2014; revisions received June 26, 2014; accepted for publication July 6, 2014; available ahead of print Aug 22, 2014.

Address for reprints: Jin-Shing Chen, MD, PhD, Department of Surgery, National Taiwan University Hospital 7, Chung-Shan South Rd, Taipei, Taiwan (E-mail: chenjs@ntu.edu.tw).

J Thorac Cardiovasc Surg 2014;148:e234-5

$0022-5223 / \$ 36.00$

Copyright (C) 2014 by The American Association for Thoracic Surgery

http://dx.doi.org/10.1016/j.jtcvs.2014.07.043
}

the fifth intercostal space along the midaxillary line after local anesthesia with 2\% lidocaine (Figure 1,B). The wound was then covered with a protector without rib spreading, and the right (operated) lung collapsed gradually as the result of an iatrogenic pneumothorax. A $5-\mathrm{mm}, 30^{\circ}$ thoracoscope was introduced through the protector into the pleural cavity with paralleling instrumentation with an endograsper or endostapler. Additionally, $0.5 \%$ bupivacaine was infiltrated to block the intercostal and vagal nerves for analgesia and inhibit the cough reflex during thoracoscopic manipulation. ${ }^{3,4}$ Uniportal anterior segmentectomy was performed (Figure 1, $C$ and D) ${ }^{3,4}$ In brief, the hilar structures, including the anterior segmental vessels and branch bronchus, were divided with endostaplers. Two anchoring lung sutures were made for 2-directional traction, facilitating the use of an articulating endostapler through the small incision without interfering with the other surgical instruments. ${ }^{5}$ Temporary positive-pressure mask ventilation was provided by the anesthesiologist to identify the segmental plane, which was also divided with an endostapler. ${ }^{3,4}$ Mediastinal nodal dissection finished the procedure with a $28 \mathrm{~F}$ chest tube left in the same incision.

During the operation, the peak $\mathrm{PaCO}_{2}$ during single-lung breathing was $47.6 \mathrm{~mm} \mathrm{Hg}$, which returned to $39.1 \mathrm{~mm}$ $\mathrm{Hg}$ after wound closure. Oxygen saturation was satisfactorily above $98 \%$ for the whole 144 -minute procedure. The final pathologic report revealed a primary lung adenocarcinoma without nodal involvement (pT1N0). The patient was discharged uneventfully on postoperative day 3 .

\section{DISCUSSION}

Awake uniportal VATS with thoracic epidural anesthesia has been recently reported for wedge resection of a peripheral lung nodule. ${ }^{2}$ In our case, we modified the awake nonintubated technique by using target-controlled sedation, along with intrathoracic intercostal and vagal blocks. Our modification enabled the intensive hilar manipulation required for major pulmonary resection and mediastinal nodal dissection in nonintubated VATS for lung cancer. ${ }^{3,4}$ In addition, an adequate level of sedation enabled our patients to tolerate these long and invasive lung resection procedures well. ${ }^{3,4}$

Because of the popularity of CT and new cancer screening policies, increasing numbers of indeterminate lung nodules 

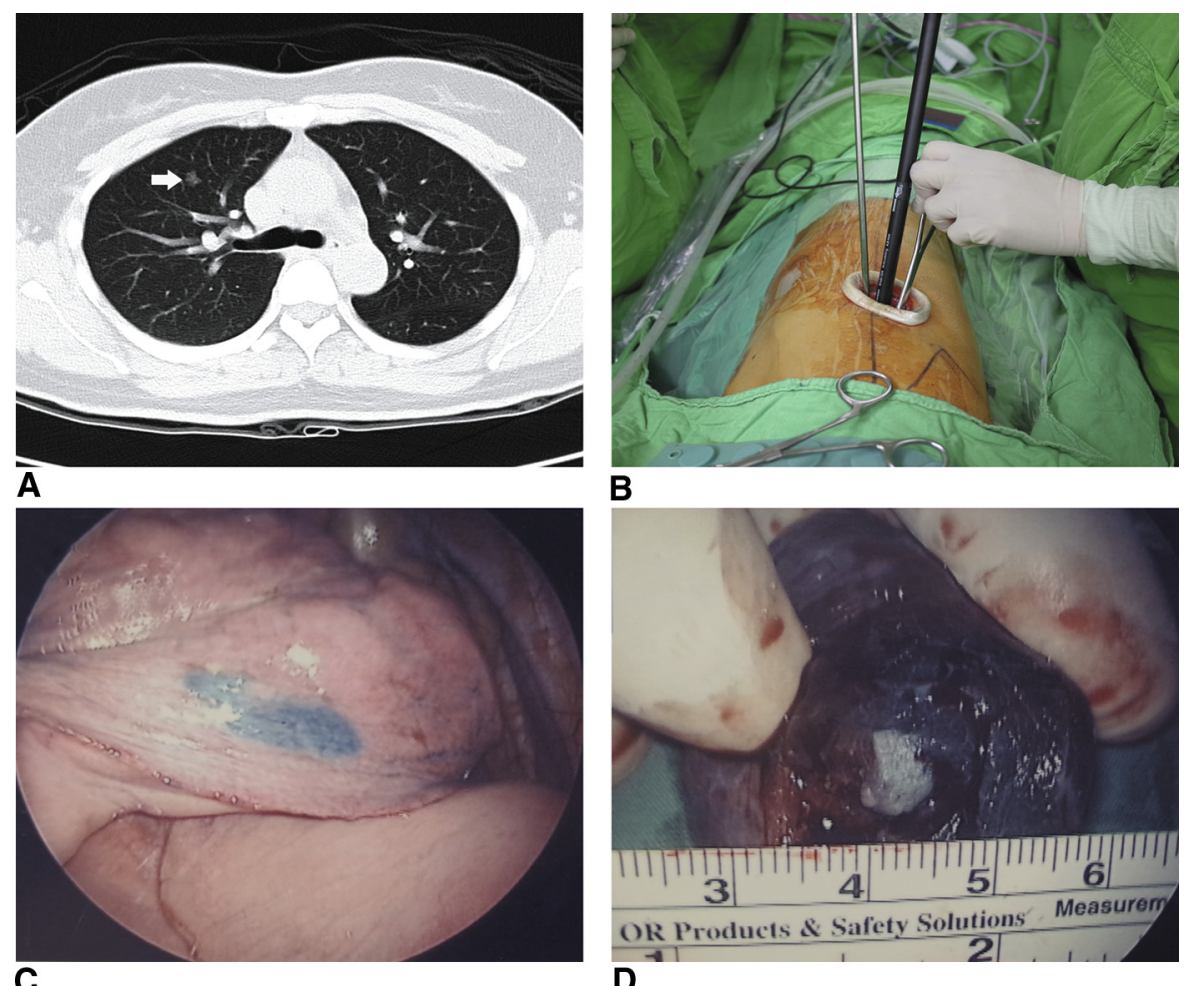

B

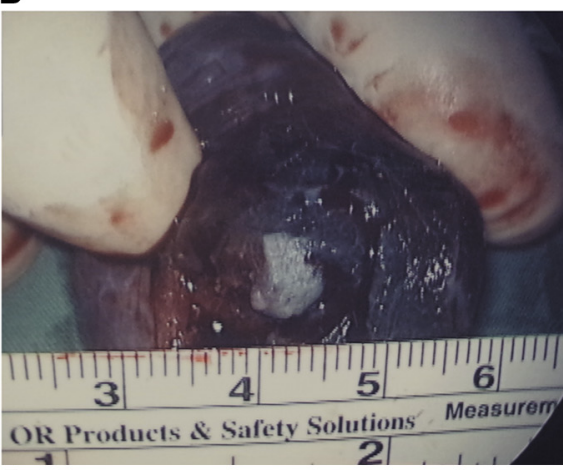

D

FIGURE 1. A, Computed tomography showed a ground-glass opacity (arrow) in the right upper lobe. B, A single 3-cm incision was made in the fifth intercostal space. C, Preoperative dye localization helped identify the small, deep nodule during surgery. D, The tumor resided in the resected anterior segment of the right upper lobe.

are necessitating surgery for either diagnostic or therapeutic purposes in the early stages. Consequently, there is increased interest in minimally invasive surgical approaches, including parenchyma-sparing resection, small or single thoracoscopic incisions, and less invasive anesthesia techniques for managing lung tumors. ${ }^{1-5}$ Although uniportal VATS has been reported to be advantageous because of the reduced postoperative residual pain and shorter hospital stays, intraoperative identification of the target lesion and instrumental manipulability without resorting to lung palpation are limited. ${ }^{1}$ We targeted the lesion with preoperative CT-guided dye localization and elevated the lesion with suture traction to facilitate the deployment of the endostaplers. $^{1,5}$ These modifications made the operation technically feasible.

In conclusion, we extended the application of nonintubated techniques to uniportal thoracoscopic segmentectomy in a patient with lung cancer. The successful management of this patient suggests the possibility of using nonintubated uniportal VATS segmentectomy as an acceptable alternative for either diagnostic or therapeutic management of indeterminate pulmonary nodules.

\section{References}

1. Rocco G. One-port (uniportal) video-assisted thoracic surgical resections-a clear advance. J Thorac Cardiovasc Surg. 2012;144:S27-31.

2. Galvez C, Bolufer S, Navarro-Martinez J, Lirio F. Awake uniportal video-assisted thoracoscopic metastasectomy after a nasopharyngeal carcinoma. J Thorac Cardiovasc Surg. 2014;147:e24-6.

3. Hung MH, Hsu HH, Chen KC, Chan KC, Cheng YJ, Chen JS. Nonintubated thoracoscopic anatomical segmentectomy for lung tumors. Ann Thorac Surg. 2013;96:1209-15.

4. Hung MH, Hsu HH, Chan KC, Chen KC, Yie JC, Cheng YJ, et al. Non-intubated thoracoscopic surgery using internal intercostal nerve block, vagal block and targeted sedation. Eur J Cardiothorac Surg. February 28, 2014 [Epub ahead of print].

5. Lee SK, Son BS, Ahn HY, Kim do H. Single-incision thoracoscopic surgery using an anchoring suture of the lung parenchyma for two-directional traction. Ann Thorac Surg. 2014;97:e89-91. 